\title{
Die Stimme im Winter
}

\section{Patienteninformation}

Unsere Stimme ist ein wesentliches Organ für Kommunikation und Ausdruck. Sie ist Arbeitsmittel und Kapital für diejenigen, die sie im Beruf benötigen. Bereits kleine Abweichungen von der Funktion können bei Personen, die in einem Stimmberuf mit Hochleistung tätig sind, wie Sänger und Schauspieler, zu erheblichen Beeinträchtigungen führen. Die Stimme reagiert auf seelische, geistige und körperliche Einflüsse und auf viele umweltbedingte Gegebenheiten.

Unser stimmbildender Apparat (Atemorgan, Kehlkopf mit seinen Stimmlippen, Artikulations- und Resonanzrohr) ist im Winter besonderen Belastungen ausgesetzt. Er bedarf daher einer speziellen Beachtung und Pflege, um Erkrankungen und Beeinträchtigungen der Stimme vorzubeugen.

\section{Allgemeine Maßnahmen}

Stärken Sie Ihre körpereigenen Abwehrkräfte gegen Erkältungen und grippale Infekte!

- Achten Sie auf einen regelmäßigen Lebensrhythmus, ausreichenden Schlaf, regelmäßige körperliche Betätigung und Gymnastik. Bewegen Sie sich an der frischen Luft: nicht zu kalte oder ozonreiche Luft, nicht im Nebel.

- Härten Sie Ihren Körper ab, z.B. mit Wechselduschen, Dampfsauna, Trockenbürsten.

- Nehmen Sie mehrere kleine Mahlzeiten zu sich: vitaminreich, fettarm, nicht blähend.

- Wählen Sie eher eine basische Kost mit viel Gemüse, Obst, Salate anstatt saure Kost mit zu viel Fleisch, Weißmehl, Süßspeisen, Alkohol und Kaffee.

- Vermeiden Sie späte Mahlzeiten, damit sich das Verdauungssystem ausruhen kann (bei Hunger am Abend trinken Sie besser eine Brühe). Trinken sie viel: Wasser, ungesüßte dünne Saftschorlen und Tee.
- Nehmen Sie die Grippeimpfung wahr, wenn Sie zum Personenkreis mit vielen Personenkontakten zählen.

- Entwickeln Sie ein Gefühl dafür, was Ihnen auch langfristig gut tut, damit Körper, Geist und Seele im Einklang sind. Dazu zählt auch eine konstruktive Art, Konflikte zu lösen.

\section{Schleimhautpflege}

$\nabla$

- Vermeiden Sie überhitzte und trockene Arbeitsräume. Diese trocknen die Schleimhaut der Nase und des Rachens aus, stören ihre Funktion und führen zu Entzündungen der Schleimhaut, die dann für Viren und Bakterien eine leichtere Angriffsfläche bietet. Sorgen Sie deswegen für Befeuchtung, Erwärmung und Reinigung der Einatemluft.

- Eine gute Feuchtigkeit der Nase erreiche Sie mit regelmäßiger lokaler Befeuchtung und ausreichender Flüssigkeitszufuhr (für den Kreislaufgesunden ca. $2-3 \mathrm{l} / \mathrm{d})$.

- Inhalationen helfen bei der Befeuchtung und Reinigung der oberen und unteren Atemwege.

- Zur Pflege der Mund- und Halsschleimhaut verwenden Sie keine alkoholhaltigen Produkte. Bei Lutschpastillen achten Sie darauf, dass sie keine scharfen oder ätherischen Öle enthalten, da letztere die Schleimhäute zusätzlich reizen.

- Trinken und essen Sie nicht zu heiß, zu kalt, zu scharf gewürzt oder zu spät (Gefahr des Rückflusses von Magensäure in der Nacht).

- Besonders im Flugzeug sollten Sänger ihre Nasenschleimhaut regelmäßig befeuchten, pro Flugstunde mindestens $500 \mathrm{ml}$ Wasser trinken und möglichst gegen eine „Maske“ ausatmen, um wenig Feuchtigkeit der Ausatmungsluft an die Umgebung abzugeben.

\section{Allgemeine Stimmpflege und medikamentöse Therapie}

Die Stimme soll nie über die individuelle Möglichkeit belastet werden. Legen Sie bei hoher Stimmbelastung Stimmpausen ein. Der erkrankte Sänger und Sprecher soll seine Stimme schonen! Dies betrifft die Sing- und die Sprechstimme in gleicher Weise. Besonders Sänger fühlen sich oft trotz einer stimmlichen Indisposition verpflichtet, eine Vorstellung zu singen. Das kann der Beginn einer Stimmerkrankung sein und zu langen Ausfallszeiten führen.

Auf dem Markt existieren zahlreiche frei verkäufliche Medikamente, die bei einer „Erkältung“ die schnellere Regeneration unterstützen können. Bei der Auswahl ist jedoch die sänger- und sprecherspezifische Medikamentenwirkung dringend $\mathrm{zu}$ beachten: Beispielsweise kann Acetylsalicylsäure (ASS) die Entstehung eines Stimmlippenhämatoms begünstigen und ist für die Hochleistungsstimme „verboten“. Auch pflanzliche Medikamente können schädigend auf die Schleimhaut wirken. So können Kamillen- oder Salbeipräparate als Auszug oder Aufguss (z.B. als Tee) die Schleimhäute austrocknen. Von (heißen) Dampfinhalationen ist bei akuten Entzündungen des Kehlkopfes abzuraten, da sie das Gewebe noch stärker anschwellen lassen.

\section{Fazit}

Bei länger dauernder Heiserkeit von ca. 2 Wochen einen Arzt für HNO, Phoniatrie konsultieren. Stimmärzte und Therapeuten können Hilfen zur Pflege und Gesunderhaltung der Stimme geben. Die Verantwortung für die eigene Stimme trägt man selbst, dessen sollte sich jeder bewusst sein.

Dr. med. Karin Joussen, Dr. med. Peter Hulin, München

überreicht durch Thieme und 